\title{
FAKTOR-FAKTOR YANG BERHUBUNGAN DENGAN INISIASI MENYUSU DINI (IMD) DI KABUPATEN BANTUL
}

\author{
Afi Lutfiyati ${ }^{1 *}$, Fitri Haryanti ${ }^{2}$, Lely Lusmilasari ${ }^{3}$
}

\author{
*1 Stikes Jenderal Achmad Yani Yogyakarta Jl. Ring road Barat, Ambarketawang, Gamping, Sleman, DIY, \\ 55294, Email: i_luth77@yahoo.com \\ 2,3 Program Studi IImu Keperawatan, FK UGM, Gedung Ismangoen Jl. Farmako, Sekip Utara, Yogyakarta \\ 55281
}

\begin{abstract}
Background: Early initiation of breastfeeding can reduce the infants mortality under the age of 28 days and can affect exclusive breastfeeding process (Roesli, 2010). In early initiation of breastfeeding and exclusive breastfeeding, there is disparities of each health center in Bantul district.

Objective: The aim of this study was to identify the association between maternal education, maternal occupation, place of childbirth, birth attendant, and health provider's support with early initiation of breastfeeding.

Methods: The study was conducted from March 23 to April 13, 2014, used crossectional design. Subjects were the entire breastfeeding mothers with infants aged 6-8 months who meet the inclusion and exclusion criteria (204 samples). Sampling with consecutive tecnique. Data obtained from secondary data and questionnaires. Data Analysis with SPSS using Chi-square test.

Results: In bivariate analysis, there was no statistically and clinically significant association between maternal education with early initiation of breastfeeding $p=0.882$; $\mathrm{OR}=0.9 ; 95 \% \mathrm{Cl}=0.44$ to 2.03 , maternal occupation $\mathrm{p}=0.463: \mathrm{OR}=1.3: 95 \% \mathrm{Cl}=0.65$ to 2.59 , and birth attendant $\mathrm{p}=0.211: \mathrm{OR}=4.8: 95 \% \mathrm{Cl}=3.69$ to 6.33. Other factors that have a statistically and clinically significant association with early initiation of breastfeeding is the place of childbitrh $\mathrm{p}=0.007 \mathrm{OR}=16.4 ; 95 \% \mathrm{Cl}=1.78$ to 150.96 and health provider's supports $\mathrm{p}=0.001: \mathrm{OR}=4.4: 95 \% \mathrm{Cl}=2.03$ to 9.68 .

Conclusions and suggestions: There is statistically and clinically significant association between place of childbirth and health provider's supports with early initiation of breastfeeding. Further research is expected involving the variable support of her husband/family with a prospective cohort to examine the association between early initiation of breastfeeding with exclusive breastfeeding.
\end{abstract}

Keywords: Early Initiation of Breastfeeding, maternal education, maternal occupation, birth attendant, place of childbirth, health provider's supports.

\section{PENDAHULUAN}

Pada satu jam pertama kelahiran merupakan periode emas yang akan menentukan keberhasilan seorang bayi untuk menyusu secara optimal, apabila satu jam pertama setelah kelahiran, bayi diberi kesempatan menyusu pertama kali maka akan membangun refleks menghisap yang baik pada bayi. ${ }^{1}$ Untuk memperoleh keberhasilan menyusui secara eksklusif, maka ada beberapa faktor yang dapat mempengaruhinya salah satunya adalah Inisiasi Menyusu Dini (IMD).

Inisiasi menyusu dini banyak memberi manfaat, yaitu terciptanya ikatan kasih sayang sebuah keluarga pada jam-jam pertama saat melahirkan, dimana sambil bayi mencari puting susu ibunya, ayah bisa berperan mengadzankan bayi di dada ibunya. Inisiasi menyusu dini juga dapat menurunkan tingkat kematian pada bayi di bawah umur 28 hari. Dalam satu tahun, empat juta bayi berusia 28 hari meninggal, 
apabila semua bayi segera setelah lahir diberi kesempatan menyusu sendiri dengan memberi kesempatan kontak kulit ibu dengan kulit bayi selama kurang lebih satu jam maka satu juta nyawa bayi dapat terselamatkan. Proses IMD berdampak juga pada penurunan angka kematian balita, yang banyak dipengaruhi oleh penerapan pemberian ASI. ${ }^{2}$

Hasil penelitian yang dilakukan Setegn et al. (2012) menyebutkan adanya hubungan antara IMD dengan pemberian ASI eksklusif dengan nilai $p=0,039$. Bayi yang diberi kesempatan IMD mempunyai kemungkinan 1,8 kali lebih besar untuk menyusu ASI secara eksklusif dibandingkan dengan bayi yang tidak diberi kesempatan IMD. ${ }^{3}$ Penelitian yang dilakukan Fikawati dan Syafiq (2003, dalam Roesli, 2010) menyebutkan bahwa bayi yang dilakukan IMD akan 8 kali lebih besar memberikan ASI eksklusif dibandingkan dengan bayi yang tidak dilakukan IMD. ${ }^{2}$

Penelitian Edmond et al. (2006) menyebutkan bahwa jika bayi diberi kesempatan menyusu dan dibiarkan melakukan kontak kulit dengan kulit dalam satu jam pertama setelah dilahirkan maka $22 \%$ nyawa bayi dibawah umur 28 hari dapat diselamatkan dan apabila bayi memulai menyusu pertamanya diatas dua jam, nyawa bayi dibawah umur 28 hari dapat terselamatkan sebesar $16 \%$. Ini berarti bahwa risiko kematian bayi di bawah umur 28 hari akan meningkat 6 kali lebih besar setiap kenaikan satu jamnya.
Di Indonesia, Data Riskesdas (2010) menyebutkan bahwa persentase proses mulai menyusui kurang dari satu jam ( $<1$ jam) setelah bayi lahir adalah 29,3\%. Sebagian besar proses mulai menyusui dilakukan pada kisaran waktu 1-6 jam setelah lahir tetapi masih ada $11,1 \%$ proses mulai menyusui dilakukan setelah 48 jam. Proses mulai menyusui $<1$ jam pada anak perempuan relatif lebih tinggi daripada anak laki-laki, demikian juga di perdesaan relatif lebih tinggi daripada di perkotaan. Menurut tingkat pendidikan dan jenis pekerjaan, tidak ada pola kecenderungan yang jelas, tetapi semakin tinggi status ekonomi terdapat kecenderungan semakin rendah. Pemberian kolostrum cukup baik, dilakukan oleh $74,7 \%$ ibu kepada bayinya.

Di Kabupaten Bantul, menurut Seksi Penyelenggaraan KIA Dinkes Bantul (2013) cakupan IMD sebesar $76,91 \%$. Paling tinggi di Puskesmas Bambanglipuro sebesar 99\%, sementara cakupan paling rendah di Puskesmas Banguntapan I sebesar 23,1\%. Di Kabupaten Bantul, meskipun cakupan ASI eksklusif pada tahun 2012 sebesar 63,51\% meningkat dari tahun 2011 sebesar 42,3\% tetapi masih tampak besar kesenjangan cakupan ASI eksklusif untuk tiap-tiap puskesmas.

\section{BAHAN DAN CARA PENELITIAN}

Penelitian ini menggunakan pendekatan kuantitatif yang menggunakan rancangan cross-sectional study. Setelah dilakukan 
pengundian maka terpilihlah Puskesmas Srandakan, Puskesmas Imogiri I, Puskesmas Bambanglipuro, Puskesmas Banguntapan II, dan Puskesmas Pleret di Kabupaten Bantul Daerah Istimewa Yogyakarta sebagai lokasi penelitian.

Sampel adalah seluruh ibu menyusui yang mempunyai bayi berusia 6-8 bulan yang tinggal dan menetap di wilayah kerja Puskesmas Pleret, Puskesmas Bambanglipuro, Puskesmas Imogiri I, Puskesmas Banguntapan II, atau Puskesmas Srandakan yang memenuhi standar kriteria inklusi dan eksklusi.

Cara pengambilan sampel menggunakan consecutive sampling, yaitu metode pemilihan sampel yang dilakukan dengan memilih semua individu yang ditemui dan memenuhi kriteria pemilihan, sampai jumlah sampel yang diinginkan terpenuhi.

Variabel dalam penelitian ini adalah:

1. Variabel bebas yaitu pendidikan ibu, pekerjaan ibu, tempat melahirkan, penolong persalinan, dan dukungan petugas kesehatan.
2. Variabel terikat yaitu pelaksanaan IMD.

Besar sampel dalam penelitian ini dihitung berdasarkan rumus besar sampel untuk uji hipotesis dua proporsi (Lemeshow et al., 2007). Besar sampel pada penelitian ini adalah 204 ibu menyusui.

Instrumen yang digunakan untuk penelitian ini adalah kuesioner. Pengambilan sampel dilakukan pada kasus dan kontrol secara bersamaan di tiap wilayah puskesmas. Puskesmas Banguntapan II sebanyak 42 orang, Puskesmas Bambanglipuro sebanyak 42 orang, Puskesmas Imogiri I sebanyak 40 orang, Puskesmas Pleret sebanyak 40 orang, dan Puskesmas Srandakan sebanyak sebanyak 40 orang sehingga total sampel yang diambil adalah 204 orang. Pengambilan data dilakukan secara serentak di 5 lokasi penelitian mulai tanggal 26 Maret 2014-13 April 2014 selama 3 minggu dengan melakukan kunjungan rumah, kunjungan ke posyandu, dan kunjungan ke Puskesmas.

HASIL DAN PEMBAHASAN

Tabel 1. Karakteristik responden penelitian ibu menyusui di Kab. Bantul ( $n=204)$

\begin{tabular}{lcc}
\hline \multirow{2}{*}{ Karakteristik Responden } & Jumlah & Persentase \\
\cline { 2 - 3 } & $\mathrm{n}$ & $\%$ \\
\hline Usia ibu & 3 & \\
$\leq 18$ tahun & 195 & 1,5 \\
19-40 tahun & 6 & 95,6 \\
$\geq 41$ tahun & & 2,9 \\
\hline Pendidikan ibu & 19 & \\
SD & 35 & 9,3 \\
SMP & 109 & 17,2 \\
SMA & 41 & 53,4 \\
Perguruan tinggi & & 20,1 \\
\hline Pekerjaan ibu & 132 & \\
Tidak bekerja & 72 & 64,7 \\
Bekerja & & 35,3 \\
\hline
\end{tabular}




\begin{tabular}{|c|c|c|}
\hline \multirow{2}{*}{ Karakteristik Responden } & Jumlah & Persentase \\
\hline & $\mathrm{n}$ & $\%$ \\
\hline \multicolumn{3}{|l|}{ Paritas } \\
\hline Primipara & 91 & 44,6 \\
\hline Multipara & 113 & 55,4 \\
\hline \multicolumn{3}{|l|}{ Cara melahirkan } \\
\hline Spontan & 155 & 76,0 \\
\hline SC & 41 & 20,1 \\
\hline Spontan dengan vakum & 8 & 3,9 \\
\hline \multicolumn{3}{|l|}{ Penolong persalinan } \\
\hline Dokter & 80 & 39,2 \\
\hline Bidan & 122 & 59,8 \\
\hline Perawat & 1 & 0,5 \\
\hline Dukun atau orang lain & 1 & 0,5 \\
\hline \multicolumn{3}{|l|}{ Jenis kelamin bayi } \\
\hline Laki-laki & 116 & 56,9 \\
\hline Perempuan & 88 & 43,1 \\
\hline \multicolumn{3}{|l|}{ Status Perkawinan } \\
\hline Kawin & 203 & 95,5 \\
\hline Tidak Kawin/Cerai & 1 & 0,5 \\
\hline \multicolumn{3}{|l|}{ Inisiasi Menyusu Dini } \\
\hline $\mathrm{Ya}$ & 161 & 78,9 \\
\hline Tidak & 43 & 21,1 \\
\hline \multicolumn{3}{|l|}{ Usia Kehamilan } \\
\hline$\leq 36$ minggu & 29 & 14,2 \\
\hline $37-40$ minggu & 167 & 81,9 \\
\hline$\geq 41$ minggu & 8 & 3,9 \\
\hline
\end{tabular}

Berdasarkan Tabel 1, dapat diketahui bahwa responden yang berusia 19 sampai 40 tahun merupakan jumlah yang terbanyak sebanyak 195 responden (95,6\%). Hal tersebut menunjukkan bahwa sebagian besar ibu melahirkan pada usia produktif dan berada pada tahap perkembangan dewasa madya.

Pada karakteristik tingkat pendidikan ibu, SMA merupakan pendidikan terakhir yang paling banyak yaitu sebanyak 109 responden (53,4\%). Hal tersebut menunjukkan bahwa sebagian besar responden telah memiliki pengetahuan dasar tentang IMD. Sebanyak 132 responden $(64,7 \%)$ merupakan ibu yang tidak bekerja, sehari-hari sebagai ibu rumah tangga (IRT). Sebanyak 113 responden (55,4\%) menyatakan bahwa mereka bukan pertama kali melahirkan.

Sebanyak 155 responden (76,0 \%) menyatakan bahwa mereka melahirkan secara spontan. Bidan merupakan penolong persalinan yang terbanyak yaitu sebanyak 122 responden $(59,8 \%)$. Jenis kelamin bayi yang paling banyak adalah laki-laki yaitu sebanyak 116 bayi (56,9\%). Sebanyak 203 responden (99,5\%) menyatakan bahwa mereka terikat perkawinan. Sebanyak 161 responden $(78,9 \%)$ menyatakan melaksanakan IMD dan sebanyak 167 
responden $(81,9 \%)$ menyatakan berada pada

usia kehamilan 37 - 40 minggu.

Tabel 2. Uji statistik chi-square faktor-faktor yang memengaruhi pelaksanaan IMD di Kab. Bantul ( $n=204)$.

\begin{tabular}{|c|c|c|c|c|c|c|}
\hline \multirow[t]{2}{*}{ Variabel } & \multicolumn{2}{|c|}{$\begin{array}{c}\text { IMD } \\
(n=161) \\
\end{array}$} & \multicolumn{2}{|c|}{$\begin{array}{c}\text { Tidak IMD } \\
(\mathrm{n}=43)\end{array}$} & \multirow[t]{2}{*}{ p } & \multirow{2}{*}{$\begin{array}{c}\text { OR } \\
95 \% \mathrm{Cl}\end{array}$} \\
\hline & $f$ & $\%$ & $f$ & $\%$ & & \\
\hline \multicolumn{7}{|l|}{ Pendidikan ibu } \\
\hline Pendidikan lanjut & 118 & 73,3 & 32 & 74,4 & \multirow[b]{2}{*}{0,882} & \multirow{2}{*}{$\begin{array}{c}0,9 \\
(0,44-2,03)\end{array}$} \\
\hline Pendidikan dasar & 43 & 26,7 & 11 & 25,6 & & \\
\hline \multicolumn{7}{|l|}{ Pekerjaan ibu } \\
\hline Tidak bekerja & 107 & 66,5 & 26 & 60,5 & \multirow{2}{*}{0,463} & \multirow{2}{*}{$\begin{array}{c}1,3 \\
(0,65-2,59)\end{array}$} \\
\hline Bekerja & 54 & 33,5 & 17 & 39,5 & & \\
\hline \multicolumn{7}{|l|}{ Tempat melahirkan } \\
\hline Pelayanan kesehatan & 160 & 99,4 & 39 & 90,7 & \multirow{2}{*}{0,007} & \multirow{2}{*}{$\begin{array}{c}16,4 \\
(1,78-150,96)\end{array}$} \\
\hline Bukan Pelayanan Kesehatan & 1 & 0,6 & 4 & 9,3 & & \\
\hline \multicolumn{7}{|l|}{ Penolong persalinan } \\
\hline Tenaga kesehatan & 161 & 100 & 42 & 97,7 & \multirow{2}{*}{0,211} & \multirow{2}{*}{$\begin{array}{c}4,8 \\
(3,69-6,33) \\
\end{array}$} \\
\hline Bukan tenaga kesehatan & 0 & 0 & 1 & 2,3 & & \\
\hline \multicolumn{7}{|l|}{$\begin{array}{cc}\begin{array}{c}\text { Dukungan } \\
\text { kesehatan }\end{array} & \text { petugas }\end{array}$} \\
\hline Ada dukungan & 142 & 88,2 & 27 & 62,8 & \multirow{2}{*}{0,001} & 4,4 \\
\hline Tidak ada dukungan & 19 & 11,8 & 16 & 37,2 & & $(2,03-9,68)$ \\
\hline
\end{tabular}

Hasil analisis Tabel 2 memperlihatkan bahwa variabel bebas yang mempunyai hubungan yang bermakna secara statistik dengan variabel terikat adalah tempat melahirkan $(p=0,007)$ dan dukungan petugas kesehatan $(p=0,001)$. Meskipun tidak bermakna tetapi penolong persalinan yang dilakukan oleh tenaga kesehatan mempunyai peluang 4,8 kali lebih besar melaksanakan IMD dibandingkan dengan persalinan yang dilakukan oleh bukan tenaga kesehatan.

Berdasarkan hasil analisis pada penelitian ini didapatkan beberapa hasil yaitu variabel ini tidak memiliki hubungan yang bermakna baik secara statistik maupun secara klinis ditandai dengan nilai $p=0,882$ dan $\mathrm{OR}=0,9$ pada nilai $\mathrm{Cl} 95 \%=0,44-2,03$.
Hasil ini sejalan dengan penelitian Khanal (2015) yang menyebutkan tidak ada hubungan antara pendidikan ibu dengan pelaksanaan IMD. ${ }^{5}$ Meskipun tidak berhubungan dengan pelaksanaan IMD, tetapi pendidikan ibu juga merupakan salah satu faktor yang memengaruhi keputusan ibu dalam memberikan ASI secara eksklusif kepada bayinya adalah tingkat pendidikan yang dimiliki oleh ibu tersebut. Semakin tinggi tingkat pendidikan seorang ibu, diharapkan mempunyai wawasan yang luas sehingga mengetahui tentang manfaat ASI eksklusif.

Chen et al. (2006) menyebutkan pendidikan ibu yang lebih tinggi mempunyai hubungan yang signifikan dengan peningkatan kelangsungan pemberian ASI 
meskipun ibu telah kembali bekerja. ${ }^{6}$ Sama halnya dengan penelitian Taveras et al. $(2003)^{7}$ yang menyatakan hubungan yang kuat antara pendidikan ibu yang rendah dengan tidak kontinyunya ibu menyusui pada 2 minggu dan 12 minggu setelah melahirkan. pendidikan merupakan faktor yang mendasar yang sangat mempengaruhi pengetahuan dan pola pikir seseorang. Ibu yang memiliki tingkat pendidikan tinggi cenderung untuk lebih terbuka terhadap informasi baru dan tidak mempercayai mitos-mitos negatif tentang ASI. Penelitian yang dilakukan oleh Leung et al. (2003) menyebutkan latar belakang pendidikan yang lebih tinggi (OR=2.87; $\quad 95 \% \mathrm{Cl}=1,92-4,27)$, secara signifikan mempengaruhi niat untuk menyusui. ${ }^{8}$ Tingkat pendidikan yang cukup tinggi menjadi jaminan bahwa mereka akan meninggalkan tradisi atau kebiasaan yang salah dalam memberi makan pada bayi, selama lingkungan sosial di tempat tinggal tidak mendukung ke arah tersebut. $^{9}$

Hasil penelitian ini sejalan dengan penelitian yang dilakukan oleh Aidam et al. $(2005)^{10}$ menyebutkan bahwa pendidikan ibu yang tinggi lebih besar kemungkinan untuk menyusui secara eksklusif dibandingkan dengan ibu yang berpendidikan rendah. Ini sejalan dengan penelitian Susilawati $(2010)^{11}$ bahwa ibu yang mempunyai pendidikan tinggi mempunyai peluang 5 kali lebih besar memberikan ASI eksklusif kepada bayinya dibandingkan dengan ibu yang berpendidikan rendah.
Variabel ini tidak memiliki hubungan yang bermakna baik secara statistik maupun secara klinis ditandai dengan nilai $p=0,463$ dan $\mathrm{OR}=1,3$ pada nilai $\mathrm{Cl} 95 \%=0,65-2,59$. Meskipun tidak ada hubungan dengan pelaksanaan IMD, tetapi status pekerjaan juga merupakan salah satu faktor yang dapat mempengaruhi keberhasilan pemberian ASI eksklusif selain IMD. Penelitian Indrawati \& Aenti (2012) ${ }^{12}$ menyebutkan ada hubungan status pekerjaan ibu dengan pemberian ASI eksklusif. Sebagian besar ibu bekerja (70\%), sebanyak $67,5 \%$ tidak memberikan ASI eksklusif. Hal ini bertolak belakang dengan penelitian Adenan et al. (2010) ${ }^{9}$ yang menyebutkan bahwa tidak ada hubungan yang bermakna antara pekerjaan ibu dengan kegagalan pemberian ASI eksklusif.

Variabel ini memiliki hubungan yang bermakna baik secara statistik maupun secara klinis antara tempat melahirkan dengan pelaksanaan IMD ditandai dengan nilai $p=0,007$ dan $O R=16,4$ pada nilai $\mathrm{Cl}$ $95 \%=1,78-150,96$. Hasil ini sejalan dengan penelitian Exavery (2015) ${ }^{13}$ yang menyebutkan bahwa ada hubungan antara tempat melahirkan dengan pelaksanaan IMD $(p=0,002)$.

Variabel ini tidak memiliki hubungan yang bermakna baik secara statistik maupun secara klinis ditandai dengan nilai $p=0,211$ dan $\mathrm{OR}=4,8$ pada nilai $\mathrm{Cl}$ 95\%=3,69-6,33. Hasil ini sejalan dengan penelitian Khanal $(2015)^{5}$ yang menyebutkan tidak ada hubungan antara penolong persalinan 
dengan pelaksanaan IMD ( $p=0,069)$. Hal ini mungkin disebabkan karena mayoritas penolong persalinan dilakukan oleh tenaga kesehatan sehingga sulit dilakukan perbandingan antara penolong persalinan yang dilakukan oleh tenaga kesehatan maupun yang dilakukan oleh dukun/orang lain.

Variabel ini memiliki hubungan yang bermakna baik secara statistik maupun secara klinis ditandai dengan nilai $p=0,001$ dan $\mathrm{OR}=4,4$ pada nilai $\mathrm{Cl} 95 \%=2,03-9,68$. Hasil ini sejalan dengan penelitian lain yang berhubungan dengan variabel saran postnatal oleh petugas kesehatan yaitu penelitian Sharma (2016) menyebutkan ada hubungan pemberian saran postnatal dengan pelaksanaan IMD $(p=0,001) .{ }^{14}$

Penelitian ini juga mendapatkan hasil bahwa semua ibu yang menjadi responden penelitian telah memberikan kolostrom kepada bayinya (100\%). Penelitian ini juga menemukan bahwasannya dari 204 responden yang menjawab kuesioner untuk variabel dukungan petugas kesehatan, terdapat 80 responden $(39,2 \%)$ menjawab petugas kesehatan tidak melibatkan suami dalam penjelasan tentang ASI eksklusif, 79 responden $(38,7 \%)$ menjawab petugas kesehatan tidak menghadirkan suami pada saat penjelasan ASI eksklusif. Upaya pemberian ASI eksklusif pada ibu menyusui salah satunya dengan mendapatkan dukungan dari keluarga dalam hal ini yang paling dekat adalah suami. Salah satu faktor yang mendukung ibu menyusui adalah adanya dukungan keluarga. ${ }^{22}$

Upaya peningkatan pemberian ASI eksklusif di Kabupaten Bantul dapat dilakukan melalui kegiatan promotif melalui kerja sama lintas program dan lintas sektor. Petugas kesehatan diharapkan memiliki kompetensi dalam memberikan penyuluhan tentang Inisiasi Menyusu Dini yang termasuk dalam kegiatan sepuluh keberhasilan dalam menyusui dan ASI eksklusif, salah satunya dengan mengantongi sertifikat sebagai konselor menyusui sehingga materi dan praktik yang akan disampaikan kepada ibu menyusui menjadi lebih kompeten. Tidak kalah penting adalah komitmen untuk memberikan pendidikan kesehatan kepada masyarakat terkait managemen laktasi dan ASI eksklusif. Untuk itu, sangat diperlukan peran pengambil keputusan bidang kesehatan, dalam hal ini Dinas Kesehatan Kabupaten Bantul melalui kerja sama lintas sektoral yang melibatkan dinas kesehata,, dinas penerangan, dinas pendidikan, dan masyarakat peduli ASI untuk meningkatkan kemampuan komunikasi, informasi, dan edukasi dengan melakukan pelatihan untuk petugas kesehatan mengenai program kegiatan sepuluh keberhasilan menyusui dan ASI eksklusif.

Peran serta masyarakat sangat diperlukan tidak hanya sekedar memberikan penyuluhan saja tetapi disertai dengan bimbingan dan motivasi kepada ibu menyusui. Petugas kesehatan akan bekerja 
sama dengan kader kesehatan dan perangkat desa/dusun setempat untuk memberikan penyuluhan kesehatan tentang pentingnya pemberian ASI eksklusif selama 6 bulan dan pemberian ASI paripurna sampai usia anak 2 tahun serta membantu ibu menyusui untuk mengatasi permasalahan yang terkait dengan pemberian ASI eksklusif.

Penelitian yang dilakukan oleh Rokhanawati (2009) menyebutkan bahwa risiko dukungan sosial suami yang rendah akan meningkatkan perilaku pemberian ASI tidak eksklusif sebesar 3,02 kali. $^{16}$ Oleh karena itu dengan adanya kegagalan petugas kesehatan dalam menghadirkan dan melibatkan suami pada saat penjelasan tentang program keberhasilan menyusui dan ASI eksklusif akan mengurangi bentuk dukungan kepada ibu menyusui agar dapat memberikan ASI eksklusif kepada bayinya.

\section{KESIMPULAN}

Tidak ada hubungan antara pendidikan ibu dengan pelaksanaan IMD. Tidak ada hubungan antara pekerjaan ibu dengan pelaksanaan IMD. Ada hubungan antara tempat melahirkan dengan pelaksanaan IMD. Tidak ada hubungan antara penolong persalinan dengan pelaksanaan IMD. Ada hubungan antara dukungan petugas kesehatan dengan pelaksanaan IMD.

Berdasarkan kesimpulan di atas, maka beberapa saran yang dapat peneliti sampaikan untuk keberhasilan program IMD pada saat persalinan dan program peningkatan pemberian ASI eksklusif sampai usia 6 bulan adalah petugas kesehatan agar memberikan waktu yang cukup setidaknya 1 jam pada saat kegiatan IMD, sehingga keberhasilan pelaksanaan IMD agar bayi dapat menemukan sendiri puting susu ibunya akan dapat terealisasi. Pada saat memberikan penjelasan terkait ASI eksklusif, petugas kesehatan hendaknya melibatkan suami agar terlibat aktif dalam pemberian ASI dengan menghadirkan suami pada saat penjelasan tersebut. Untuk peneliti selanjutnya agar dapat melibatkan variabel dukungan suami/keluarga untuk melihat hubungannya dengan pemberian ASI eksklusif. Perlu adanya penelitian dengan metode kohort prospektif untuk melihat hubungan antara IMD dengan pemberian ASI eksklusif.

\section{KEPUSTAKAAN}

1. Moore, E.R., Anderson, G.C., Bergman, N. (2007). Early skin-to-skin Contact for Mothers and their Healthy Newborn Infants (Review), The Cochrane Library (3).

2. Roesli, U. (2010). Inisiasi Menyusu Dini plus ASI Eksklusif. Jakarta : Pustaka Bunda.

3. Setegn, T. et al. (2012). Factors Associated with Exclusive Breastfeeding Practices Among Mothers in Goba District, South East Ethiopia: a CrossSectional Study. International Breastfeeding Journal. 7(17).

4. Edmond, K.M. et al. (2006). Delayed Breastfeeding Initiation Increases Risk of Neonatal Mortality. Pediatrics. Vol. 117 (3): 380-386.

5. Khanal, V., Scott, J.A., Lee, A.H., Rajendra, K., Binns, C.W. (2015). 
International Journal of Environmental Research and Public Health. 14 August.

6. Chen, Y.C., Wu, Y.C. \& Chien, W.C. (2005). Effects of Works-related Factors on the Breastfeeding Behavior of Working Mother in Taiwanese Semiconductor Manufacture: A Cross-sectional Survey. BMC Public Health. 6(106): 1186-1471.

7. Taveras, E.M. et al. (2003). Clinician Support and Psychosocial Risk Factors Associated with Breastfeeding Discontinuation. Pediatrics. 112(1): 108115.

8. Leung, TF. et al. (2003). Sociodemographic and Atopic Factors Affecting Breastfeeding Intention in Chinese Mothers. Journal of Paediatrics and Child Health. 39:460-464.

9. Adenan, Z. et al. (2010). Faktor-faktor yang Mempengaruhi Kegagalan Pemberian ASI Eksklusif di Wilayah Kerja Puskesmas Sungai Besar Banjarbaru pada Tahun 2009. Berkala Kedokteran. 8(1): 10-16.

10. Aidam, B.A. et al. (2005). Factors Associated with Exclusive Breastfeeding in Accra, Ghana. European Journal of Clinical Nutrition. 59:789-796.

11. Susilawati. (2010). Pengaruh Inisiasi Menyusu Dini Terhadap Kelangsungan
Pemberian ASI Eksklusif di Kabupaten Kampar Riau. Tesis. Yogyakarta: UGM.

12. Indrawati, T., Aenti, ER. (2012). Hubungan Status Pekerjaan Ibu dengan Pemberian Air Susu Ibu (ASI) Eksklusif pada Bayi Saat Usia 0-6 Bulan di Bidan Praktik Mandiri Kota Semarang. Dinamika Kebidanan. 2(2):-

13. Exavery, A., Kante, A.M., Hingora, A., Phillips, J.F. (2015). Determinants of Early Initiation of Breastfeeding in Rural Tanzania. International Breastfeeding Journal. 10(27).

14. Sharma, A., Thakur, P.S., Tiwari, R., Kasar, P.K., Sharma, R., Kabirpanthi, V. (2016). Factors Associated with Early Initiation of Breastfeeding among Mothers of Tribal Area of Madhya Pradesh, India: A Community Based Cross Sectional Study. International Journal of Community Medicine and Public Health. 3(1): 194-199.

15. Arora, S. et al. (2000) Mayor Factor Influencing Breastfeeding Rates: Mothers Perception of Fathers Attitute and Milk Supply. Pediatrics. 106(5):1-5

16. Rokhanawati, D. (2009). Dukungan Sosial Suami dan Perilaku Pemberian ASI Eksklusif di Kabupaten Bantul Yogyakarta. Tesis. Yogyakarta: UGM. 